\section{References}

1 Appleby J. Patient choice in the NHS. BMJ 2004; 329: 61-2.

2 Brown N, Bhugra D. 'New' professionalism or professionalism derailed? Psychiatr Bull 2007; 31: 281-3.

3 Fulford KWM. Ten principles of values-based medicine. In The Philosophy of Psychiatry: A Companion (ed J Radden): 205-34. Oxford University Press, 2004

4 Royal College of Psychiatrists. Mental Health and Social Inclusion. Making Psychiatry and Mental Health Services Fit for the 21st Century. Royal College of Psychiatrists, 2009 (http://www.rcpsych.ac.uk/pdf/ social\%20inclusion\%20position\%20statement09.pdf).

5 Care Services Improvement Partnership, Royal College of Psychiatrists, Social Care Institute for Excellence. A Common Purpose: Recovery in Future Mental Health Services. SCIE, 2007 (http://www.spn.org.uk/ fileadmin/SPN_uploads/Documents/Papers/SPN_Papers/recovery2.pdf).

6 Bhugra D. The new curriculum for psychiatric training. Adv Psychiatr Treat 2006; 12: 393-6.

7 Faulkner A, Thomas P. User-led research and evidence-based medicine. Br J Psychiatry 2002; 180: 1-3.
8 Glover G, Arts G, Babu KS. Crisis resolution/home treatment teams and psychiatric admission rates in England. Br J Psychiatry 2006; 189: 441-5.

9 Howard LM, Rigon E, Cole L, Lawlor C, Johnson S. Admission to women's crisis houses or to psychiatric wards: women's pathways to admission. Psychiatr Serv 2008; 59: 1443-9.

10 Kurtz Z, James C. What's New: Learning from the CAMHS Innovation Projects. Department of Health, 2002.

11 Raue PJ, Schulberg HC, Heo M, Klimstra S, Brice ML. Patients' depression treatment preferences and initiation, adherence, and outcome: a randomized primary care study. Psychiatr Serv 2009; 60 337-43.

12 Hill S, Laugharne R. Patient choice survey in general adult psychiatry. Psychiatry On Line 2006 (http://www.priory.com/psych/cornwall.pdf).

13 Olofinjana B, Taylor D. Antipsychotic drugs - information and choice: a patient survey. Psychiatr Bull 2005; 29: 369-71.

14 Roberts G, Dorkins E, Wooldridge J, Hewis E. Detained - what's my choice? Part 1: Discussion. Adv Psychiatr Treat 2008; 14: 172-80.

\title{
Does the scientific evidence support the recovery model?
}

\author{
Richard Warner ${ }^{1}$
}

The Psychiatrist (2010), 34, 3-5, doi: 10.1192/pb.bp.109.025643

'University of Colorado, and Colorado Recovery, Boulder, Colorado, USA Correspondence to Richard Warner (rwarner@coloradorecovery.com)
Summary This editorial addresses the question of whether some of the basic tenets of the recovery model - optimism about outcome, the value of work, the importance of empowerment of patients and the utility of user-run programmes are supported by the scientific research.

Declaration of interest None.

\section{Recovery model}

The recovery model is a social movement that is influencing mental health service development around the world. It refers to the subjective experience of optimism about outcome from psychosis, to a belief in the value of the empowerment of people with mental illness, and to a focus on services in which decisions about treatment are taken collaboratively with the user and which aim to find productive roles for people with mental illness. ${ }^{1-3}$ Flowing from this model is a renewed interest in educating users about illness management, in tackling stigma and in the creation of service user-run services that offer advocacy, mentoring and peer support via such mechanisms as userrun drop-in centres. Collaborative models, like the psychosocial clubhouse and educational programmes that involve both professionals and clients as teachers, are seen as important elements of recovery-oriented services. ${ }^{1-3}$
A social movement is a form of social action based on shared values and aspirations, and it is not necessarily founded upon scientific evidence. Do the research data, in fact, support optimism about outcome from serious mental illness, the value of work, the importance of empowerment and other tenets of the recovery model?

\section{Recovery from schizophrenia}

A large body of data, including several recent studies, suggest that optimism about outcome from schizophrenia is justified. A meta-analysis of over a hundred outcome studies in schizophrenia conducted in high-income countries throughout the 20th century ${ }^{4}$ assessed whether individuals had achieved 'social recovery' (economic and residential independence and low social disruption) or 'complete recovery' (loss of psychotic symptoms and return to the 
pre-illness level of functioning). The analysis revealed a substantial rate of recovery from schizophrenia throughout the century - around $20 \%$ complete recovery and $40 \%$ social recovery (which includes those who achieved complete recovery). Recent support for this level of recovery comes from various sources. Lambert and colleagues $^{5}$ in Hamburg, Germany, found that $17 \%$ of nearly 400 patients with never previously treated schizophrenia achieved complete recovery after a 3-year followup. A Chicago-based 15-year prospective follow-up study of 64 people with schizophrenia, conducted by Harrow \& Jobe, ${ }^{6}$ found $19 \%$ to be in complete recovery. An 8-year follow-up of 67 individuals with non-affective psychosis in Dublin found $39 \%$ to be in social recovery. ${ }^{7}$ These recent results are closely in line with the results of the 20thcentury meta-analysis. ${ }^{4}$ It emerges that one of the most robust findings about schizophrenia is that a substantial proportion of those who present with the illness will recover completely or with good functional capacity.

Another recent publication, the International Study of Schizophrenia, offers a comparison of outcome from schizophrenia in high-income and low- and middle-income countries. ${ }^{8}$ The study pulls together data from several multinational studies of long-term outcome from schizophrenia-incidence cohorts from two World Health Organization (WHO) studies and two studies in Chennai and Hong Kong. Also included are data from prevalence cohorts in the WHO International Pilot Study of Schizophrenia and another study conducted in Beijing. The resulting analysis includes over 1000 individuals from 16 centres around the world followed up after 12-26 years. From this amalgam of studies, conducted in a variety of settings around the world and spanning the last quarter of the 20th century, we learn that the course and outcome of schizophrenia are superior in low- and middle-income countries. Five of the ten centres with the highest proportion of clients rated 'recovered' on the Bleuler symptom scale were in low- and middle-income countries. Kraepelin's view that a deteriorating course is a hallmark of the illness proves not to be true; heterogeneity of outcome, both in terms of symptoms and functioning, is the signature feature.

\section{Work and outcome from schizophrenia}

The belief that working helps people recover from psychosis is supported by macroeconomic and individual level data. At the macroeconomic level, outcome from schizophrenia worsens during economic downturns ${ }^{4}$ and hospital admissions for working-age individuals with psychosis increase. ${ }^{9}$ At an individual level, numerous controlled studies conducted since the early 1990s have identified improved non-vocational outcomes for individuals with serious mental illness who are working. Participation in an effective vocational programme or having paid employment is associated with reduced psychiatric hospital admissions, reduced healthcare costs and less intensive positive and negative symptoms of psychosis. Successful work programmes lead to increased quality of life, improved self-esteem, enhanced functioning, and an expanded social network. ${ }^{3,10,11}$ These controlled studies of the nonvocational benefits of work only became feasible in the 1990s with the development of an effective vocational intervention for people with mental illness - supported employment. A series of randomised controlled trials, two meta-analyses ${ }^{12,13}$ and a recent review ${ }^{14}$ have demonstrated the effectiveness of this model in the USA. Recent studies have confirmed that this American model is also effective outside the USA. ${ }^{11,15,16}$

\section{Empowerment}

A central tenet of the recovery model is that empowerment of the user is important in achieving good outcome in serious mental illness. To understand why this may be so, it is important to appreciate that people with mental illness may feel disempowered, not only as a result of involuntary confinement or paternalistic treatment, but also by their own acceptance of the stereotype of a person with mental illness. People who accept that they have mental illness may feel driven to conform to an image of incapacity and worthlessness, becoming more socially withdrawn and adopting a disabled role. As a result, their symptoms may persist and they may become dependent on treatment providers and others. Thus, insight into one's illness may be rewarded with poor outcome. ${ }^{4}$

This view is supported by an early study of people with serious mental illness which found that those who accept that they are mentally ill and have a sense of mastery over their lives (an internal locus of control) have the best outcomes. However, those who accept the label of mental illness tend to have lower self-esteem and an external locus of control, and those who find the mental illness label to be most stigmatising have the weakest sense of mastery. Thus, internalised stigma undermines the possibility that insight will lead to good outcome. ${ }^{17}$

Similarly, in a recent cluster analysis of 75 people with schizophrenia, Lysaker and colleagues $^{18}$ found that individuals who demonstrated high levels of insight and low levels of internalised stigma demonstrated the highest functioning, but those with high insight and high internalised stigma experienced the lowest levels of hope and self-esteem. The 15-year naturalistic follow-up study of people with schizophrenia by Harrow \& Jobe, cited earlier, provides further evidence that empowerment is an aid to recovery. ${ }^{6}$ The participants who were no longer taking antipsychotic medication, many of whom were in a sustained period of recovery, were more likely to have had an internal locus of control when evaluated 5-10 years earlier. Another recent study of over 100 people with schizophrenia, applying path analysis, demonstrated that an internalised sense of stigma is associated with avoidant coping (similar to an external locus of control), social avoidance and depression: these relationships were mediated by the effect of internalised stigma on hope and self-esteem. ${ }^{19}$ In a similar study applying structural equation modelling to data gathered from 172 outpatients with schizophrenia, Vauth and colleagues ${ }^{20}$ found that a large proportion of depression and decreased quality of life could be explained by eroded empowerment and that much of the decreased empowerment was explained by high levels of anticipatory stigma. The conclusion we may draw from this body of research is that the empowerment of people with mental illness and helping them reduce their internalised sense of stigma are as important as helping 
them find insight into their illnesses. Until now, however, more effort has been expended on the last than on the former two factors.

An important means of empowering patients is to involve them in decisions about their illness. A recent northern Italian study, however, indicates that psychiatrists (in an excellent service system) rate poorly in practising this approach; ${ }^{21}$ psychiatrists in the Netherlands performed better. ${ }^{22}$

Another route to empowerment is to offer patients peer support (via user-operated services), which benefits both the recipient of services, who is exposed to a positive role model, and the user provider of services, who gains confidence by being of assistance to others. Corrigan, ${ }^{23}$ in a survey of over 1800 people with psychiatric disability, found that participation in peer support was significantly associated with enhanced outcome and recovery. Sells and colleagues $^{24}$ found that peer service providers were perceived by clients to be more validating but that they were able to achieve improved short-term outcomes when they found it necessary to challenge clients' attitudes and behaviours. Resnick \& Rosenhan, ${ }^{25}$ in a Veterans Affairs study, found that people with severe mental illness who participated in a vet-to-vet peer education and support programme scored significantly higher on measures of empowerment, functioning and well-being than an earlier cohort who were not exposed to the programme.

\section{Conclusion}

The recovery model refers both to subjective experiences of optimism, empowerment and interpersonal support, and to the creation of positive, recovery-oriented services. Optimism about outcome from schizophrenia is supported by the research data. One of the most robust findings in schizophrenia research is that a substantial proportion of those with the illness will recover completely and many more will regain good social functioning. Much recent research suggests that working helps people recover from schizophrenia and advances in vocational rehabilitation have made this more feasible. A growing body of research supports the concept that empowerment is an important component of the recovery process and that user-driven services and a focus on reducing internalised stigma are valuable in empowering the person with schizophrenia and improving the outcome from illness. Further controlled studies of empowerment-oriented interventions are required to demonstrate convincingly that a focus on this factor will yield better outcomes in psychosis.

\section{About the author}

Richard Warner is Clinical Professor of Psychiatry, University of Colorado, and Director, Colorado Recovery, Boulder, Colorado, USA.

\section{References}

1 Liberman RP. Recovery from Disability: Manual of Psychiatric Rehabilitation. American Psychiatric Publishing, 2008.

2 Shepherd G, Boardman J, Slade M. Making Recovery a Reality. Sainsbury Centre for Mental Health, 2008.

3 Leff J, Warner R. Social Inclusion of People with Mental IIIness. Cambridge University Press, 2006
4 Warner R. Recovery from Schizophrenia: Psychiatry and Political Economy (3rd edn). Brunner-Routledge, 2004.

5 Lambert M, Naber D, Schacht A, Wagner T, Hundemer HP, Karow A et al. Rates and predictors of remission and recovery during 3 years in 393 never-treated patients with schizophrenia. Acta Psychiatr Scand 2008; 118: 220-9.

6 Harrow M, Jobe TH. Factors involved in outcome and recovery in schizophrenia patients not on antipsychotic medications: a 15-year multi follow-up study. J Nerv Ment Dis 2007; 195: 406-14.

7 Crumlish N, Whitty P, Clarke M, Browne S, Kamali M, Gervin M, et al. Beyond the critical period: longitudinal study of 8-year outcome in firstepisode non-affective psychosis. Br J Psychiatry 2009; 194: 18-24.

8 Hopper K, Harrison G, Janca A, Sartorius N (eds). Recovery from Schizophrenia: An International Perspective. A Report of the WHO Collaborative Project, the International Study of Schizophrenia. Oxford University Press, 2007.

9 Brenner MH. Mental Illness and the Economy. Harvard University Press, 1973.

10 Bond GR, Resnick SG, Drake RE, Xie H, McHugo GJ, Bebout RR. Does competitive employment improve non-vocational outcomes for people with severe mental illness? J Consult Clin Psychol 2001; 69: 489-501.

11 Burns $T$, Catty J, Becker T, Drake RE, Fioritti A, Knapp M, et al. The effectiveness of supported employment for people with severe mental illness: a randomised controlled trial. Lancet 2007; 370: 1146-52.

12 Crowther RE, Marshall M, Bond GR, Huxley P. Helping people with severe mental illness to obtain work: systematic review. BMJ 2001; 322: 204-8.

13 Twamley EW, Jeste DV, Lehman AF. Vocational rehabilitation in schizophrenia and other psychotic disorders: a literature review and meta-analysis of randomized controlled trials. J Nerv Ment Dis 2003; 191: $515-23$.

14 Bond GR. An update on randomized controlled trials of evidence-based supported employment. Psychiatr Rehabil J 2008; 31: 280-90.

15 Killackey E, Jackson HJ, McGorry PD. Vocational intervention in firstepisode psychosis: individual placement and support $v$. treatment as usual. Br J Psychiatry 2008; 193: 114-20.

16 Latimer EA, Lecomte T, Becker DR, Drake RE, Duclos I, Piat M, et al Generalisability of the individual placement and support model of supported employment: results of a Canadian randomised controlled trial. Br J Psychiatry 2006; 189: 65-73.

17 Warner R, Taylor D, Powers M, Hyman J. Acceptance of the mental illness label by psychotic patients: effects on functioning. Am J Orthopsychiatry 1989; 59: 398-409.

18 Lysaker PH, Davis LW, Warman DM, Strasburger A, Beattie N. Stigma, social function and symptoms in schizophrenia and schizoaffective disorder: associations across six months. Psychiatry Res 2007; 149: 89-95.

19 Yanos PT, Roe D, Marus K, Lysaker PH. Pathways between internalized stigma and outcomes related to recovery in schizophrenia spectrum disorders. Psychiatr Serv 2008; 59: 1437-42.

20 Vauth R, Kleim B, Wirtz M, Corrigan PW. Self-efficacy and empowerment as outcomes of self-stigmatizing and coping in schizophrenia. Psychiatry Res 2007; 150: 71-80.

21 Goss C, Moretti F, Mazzi MA, Del Piccolo L, Rimondini M, Zimmermann C. Involving patients in decisions during psychiatric consultations. $\mathrm{Br} J$ Psychiatry 2008; 193: 416-21.

22 Goossensen A, Zijlstra P, Koopmanschap M. Measuring shared decision making processes in psychiatry: skills versus patient satisfaction. Patient Educ Couns 2007; 67: 50-6.

23 Corrigan PW. Impact of consumer-operated services on empowerment and recovery of people with psychiatric disorders. Psychiatr Serv 2006; 57: 1493-6.

24 Sells D, Black R, Davidson L, Rowe M. Beyond generic support: incidence and impact of invalidation in peer services for clients with severe mental illness. Psychiatr Serv 2008; 59: 1322-7.

25 Resnick SG, Rosenheck RA. Integrating peer-provided services: a quasiexperimental study of recovery orientation, confidence and empowerment. Psychiatr Serv 2008; 59: 1307-14. 